\title{
NÍVEL DE PROFICIÊNCIA EM INGLÊS DE PROFESSORES EM FORMAÇÃO INICIAL: UM ESTUDO SOBRE A VISÃO DE DOCENTES DE UM CURSO DE LETRAS E DE ESPECIALISTAS DA ÁREA
}

\author{
Eliana KOBAYASHI \\ Barbara Cristina GALLARDO²
}

\section{http://dx.doi.org/10.21165/gel.v18i2.3107}

Resumo: Este trabalho traz um recorte dos resultados de um amplo estudo realizado sobre o nível de proficiência em língua inglesa dos alunos em diferentes etapas do curso de Letras (Português/Inglês) de uma universidade pública, e questiona a relevância da aplicação de testes de proficiência para acompanhar a evolução dos alunos, do processo seletivo à graduação. São discutidas, neste artigo, as vozes de diferentes atores envolvidos direta e indiretamente no contexto investigado, como docentes e coordenador do curso, e especialistas da área de formação de professores e de avaliação em língua estrangeira. De natureza metodológica qualitativa, este trabalho utiliza entrevistas com questões abertas e a triangulação de dados para analisar em profundidade os dados coletados. Entre os resultados, foram identificadas visões distintas sobre o assunto, como um nível de proficiência mínimo variando entre $\mathrm{B} 1$ e C1 do Quadro Comum Europeu de Referência para Línguas (Common European Framework of References for Languages - CEFR) a ser atingido no final do curso, as limitações das provas do vestibular e do Exame Nacional do Ensino Médio (ENEM) diante das habilidades linguísticas necessárias para o curso de Letras e a importância da aplicação de testes de proficiência, em diferentes momentos do curso.

Palavras-chave: Nível de proficiência. Formação de professores de inglês. Testes de proficiência em língua inglesa.

\footnotetext{
1 Instituto Federal de Educação, Ciência e Tecnologia de São Paulo (IFSP), Suzano, São Paulo, Brasil; likobayashi@ifsp.edu.br; http://orcid.org/0000-0003-0021-8096

2 Universidade do Estado de Mato Grosso (UNEMAT), Tangará da Serra, Mato Grosso, Brasil; barbarag@unemat.br; http://orcid.org/0000-0001-8055-0990
} 
- Nível de proficiência em inglês de professores em formação inicial: um estudo sobre a visão de docentes de um curso de Letras e de especialistas da área

\title{
ENGLISH PROFICIENCY LEVEL OF FUTURE TEACHERS: A STUDY ON TEACHERS AND ASSESSMENT SPECIALISTS'VIEWS
}

\begin{abstract}
This study presents the preliminary results of a large investigation on the students' level of English proficiency at different stages of a Language Teacher Education Course (Portuguese/English) at a public university. It questions the relevance of proficiency tests application to monitor the students' progress in the English language, from the admission process to graduation. In this paper, the voices of different actors directly and indirectly involved in the investigated context are discussed, such as professors, course coordinators and language assessments, and teaching education researchers. This is a qualitative study that used interviews with open questions and data triangulation to analyze in-depth the collected data. Among the results, distinct views on the subject were identified, such as a minimum proficiency level ranging from $\mathrm{B} 1$ to $\mathrm{C} 1$ (CEFR) to be reached by the end of the course, the limitations of the entrance exam and ENEM to test the expected language skills to attend the language course successfully, and the importance of applying proficiency tests at different stages of the course.
\end{abstract}

Keywords: Proficiency level. English language teacher education. English language proficiency tests.

\section{Introdução}

Entre as várias competências esperadas de um professor de inglês está a capacidade de utilizar a língua a qual tem a responsabilidade de ensinar aos seus alunos. No entanto, tem sido um desafio para os cursos de Letras que oferecem tanto a dupla licenciatura (Português/Inglês) quanto a licenciatura única (Inglês) preparar os futuros professores de língua inglesa. Estudos na área apontam para a insuficiência no ensino e na avaliação da competência linguístico-comunicativa nesses cursos de graduação (GALLARDO; OLIVEIRA, 2018; GIMENEZ, 2019; LEFFA, 2005; PAIVA, 2011).

Portanto, o desenvolvimento de investigações que busquem a melhor compreensão sobre os problemas que ocorrem na formação de professores e promovam reflexões e encaminhamentos para essa área apresenta-se como relevante e urgente. A importância do inglês como língua que possibilita a participação no mundo globalizado já vem sendo discutida há tempos (CRYSTAL, 2003; GRADDOL, 2000; JENKINS, 2000; LANKSHEAR, 1997). Mesmo assim, o ensino no Brasil parece não mostrar reações de uma maneira mais abrangente, uma vez que professores que ainda não dominam a língua podem chegar à sala de aula de escolas. 
É inquestionável, porém, a existência de inúmeros fatores em um processo de ensino e aprendizagem no contexto universitário que atuam concomitantemente e podem constituir e, consequentemente, influenciar no baixo nível de proficiência na língua inglesa a ser aprendida pelos alunos. Por esse motivo, um olhar mais crítico em tais obstáculos torna-se necessário, na busca por encaminhamentos e reflexões no ensino de inglês na universidade.

A língua inglesa é a habilidade-mor no processo de formação do professor em formação inicial. Ademais, para atender adequadamente à sociedade, graduados, de qualquer curso, devem ser capazes de desempenhar o que aprenderam da melhor forma possível. No caso de um professor de inglês, é, sinteticamente, saber ensinar inglês aos seus alunos, o que pressupõe a utilização da língua por ele mesmo.

Diante dessas reflexões, realizamos um amplo estudo focalizando o curso de licenciatura em Letras de uma universidade pública. Neste artigo, fizemos um recorte de tal estudo, com os seguintes objetivos: (1) apresentar a percepção do coordenador do curso e dos professores que ministram as disciplinas de inglês sobre o nível de proficiência dos alunos, no início e no final do curso e sobre o nível de proficiência necessário que deve ser atingido pelo aluno até o final do curso; (2) apresentar a visão de especialistas sobre a relevância da aplicação de testes de proficiência para auxiliar o progresso dos alunos na língua.

É importante ressaltar que se reconhece aqui que a formação de um professor de um professor de inglês abrange diversos outros aspectos, não se restringindo, sob hipótese alguma, a sua capacidade de usar a língua inglesa. Por outro lado, também é de conhecimento comum que um certo nível de proficiência na língua em que se ensina é fundamental.

Neste estudo, parte-se do pressuposto de que a ausência de clareza e o conflito de percepções podem ser algumas das razões por parte dos alunos, professores e coordenação do curso analisado sobre as descrições e especificações da capacidade de utilização da língua inglesa exigidas de um professor em formação, do momento em que ingressa no curso até o ano de sua graduação. Para tanto, é focalizado neste artigo um recorte dos resultados da investigação conduzida, abrangendo as vozes de determinados atores do contexto: docentes das disciplinas relacionadas ao inglês e coordenador do curso, assim como pesquisadores da área de ensino e avaliação de língua.

O artigo está dividido em três seções. Até aqui, explicitamos o contexto, a justificativa e os objetivos do trabalho. Na sequência desta introdução, apresentamos as principais teorias que norteiam a investigação. Na seção metodologia, encontram-se a natureza 
- Nível de proficiência em inglês de professores em formação inicial: um estudo sobre a visão de docentes de um curso de Letras e de especialistas da área

do estudo, o cenário, os participantes e os instrumentos de coleta. Na terceira parte, são discutidos os principais resultados alcançados. O artigo é finalizado com algumas considerações sobre os possíveis encaminhamentos e reflexões.

O debate no Brasil sobre o nível de proficiência em inglês dos professores dessa língua não é algo recente. Pelo contrário, Almeida Filho (1992) já problematizava essa questão há quase duas décadas. Desde então, muitos outros estudos foram realizados e apontavam para: fragilidades na formação docente em duplas licenciaturas, como Português/Inglês (PAIVA, 2003, 2004); a relevância de testes de proficiência específicos para professores visando provocar uma mudança desse quadro (CONSOLO; TEIXEIRA DA SILVA, 2007; CONSOLO; TEIXEIRA DA SILVA, 2014); problemas para o desenvolvimento das habilidades linguístico-comunicativas no currículo de cursos de formação de professores (GIMENEZ, 2005); professores já atuantes em sala de aula com um baixo nível de proficiência (GIMENEZ; MATEUS, 2002), entre outros aspectos.

É importante ressaltar que as Diretrizes Curriculares para os Cursos de Letras, estabelecidas em 2001, fornecem princípios e orientações gerais quanto a aspectos como objetivos, necessidade de flexibilização curricular, perfil dos formandos, competências e habilidades e avaliação dos cursos de bacharelado e licenciatura. Entretanto, essas Diretrizes mostram-se muito superficiais e pouco exploram a questão do nível de proficiência dos alunos de Letras, limitando a sua descrição ao "domínio do uso da língua portuguesa ou de uma língua estrangeira, nas suas manifestações oral e escrita, em termos de recepção e produção de textos" (BRASIL, 2001, p. 30). Entretanto, o conceito de domínio pode ser relativizado de acordo com as especificações determinadas pelo perfil do usuário da língua e o contexto de sua utilização. Além disso, estudos questionam a adequação da legislação à realidade do ensino de língua inglesa no Brasil (WALKER, 2003; PAIVA, 2003).

Dessa forma, como consequência dessa orientação das Diretrizes, as universidades passam a estabelecer seus próprios perfis de proficiência em língua estrangeira para os futuros licenciados. Por outro lado, como revela Marcelino (2010) em sua investigação dos projetos pedagógicos de instituições formadoras de licenciados em língua inglesa, foram identificados diversos problemas, tais como, o baixo nível de proficiência dos ingressantes, carga horária das disciplinas de inglês insuficiente e falta de clareza sobre as concepções de competências e habilidades a serem desenvolvidas durante a graduação.

Em uma perspectiva mais abrangente, focalizando especificamente no ensino e na avaliação de inglês, é possível identificar a existência de níveis de proficiência claramente especificados em materiais didáticos e em testes internacionais. Nesse caso, livros didáticos 
de inglês, normalmente comercializados no mercado nacional e internacional, indicam o nível de proficiência por classificações como, por exemplo, intermediário ou avançado e, também, pela escala do Quadro Europeu Comum de Referência (Common European Framework for References of Languages - CEFR), doravante CEFR, ou ainda, por níveis correspondentes à determinada proficiência, como o $B 2$ First, chamado anteriormente de FCE, da Cambridge Language Assessment; de inglês para fins acadêmicos, o IELTS, o TOEFL e o TOEIC, este voltado para o ambiente de trabalho. Apesar desses dois últimos exames apresentarem os resultados dos candidatos por meio de pontuações e o IELTS por band scores, todos também trazem comparativos com as escalas do CEFR ${ }^{3}$. Assim, os candidatos sabem a qual nível do quadro a pontuação que atingiram equivale.

Essa discussão objetiva fundamentar a proposição deste estudo, ressaltando a importância de se conhecer o nível de proficiência fundamentado em uma referência. Considerando que, atualmente, estudantes de língua inglesa e candidatos de testes internacionais estão em contato com esse parâmetro, é esperado que um professor de língua inglesa, que irá futuramente ensinar, esclarecer e preparar esse mesmo público, conheça o nível mínimo exigido para a sua profissão, tanto no inglês geral quanto no inglês específico de sua atuação.

Além disso, uma vez que o aluno ingressante no curso de Letras já apresente um nível de proficiência de domínio mais independente da língua, como o B2, por exemplo, torna-se menos desafiador desenvolver, na universidade, as habilidades linguísticas mais específicas e características da profissão de professor. Sem a aplicação de um instrumento avaliativo, não é possível identificar a proficiência desses alunos.

A aplicação de testes de inglês como um caminho para contribuir com o ensino e aprendizado de inglês, de professores em formação, e com a consequente elevação do nível de proficiência de alunos tem sido intensamente discutida na literatura da área, pois consiste em um recurso utilizado por governo e instituições de ensino de vários países, tais como, Israel (SHOHAMY; REVESE BEJARANO, 1986; FERMAN, 2004), China (QI, 2004; CHENG, 1997, 2005; LUMLEY; STONEMAN, 2000) e Japão (NAGAO; TADAKI; TAKEDA; WICKING, 2012; WATANABE, 2004), como uma tentativa de promover efeito retroativo positivo. Conforme Alderson e Wall (1993), em seu estudo seminal sobre o assunto, efeito retroativo são influências positivas ou negativas que exames exercem no ensino e na aprendizagem. É, assim, uma ação relevante para ser aplicada.

3 Disponível em: https://www.ets.org/toefl/score-users/scores-admissions/compare. Acesso em: 25 maio 2020. Disponível em: http://yourenglishtest.com/article/index/art/54. Acesso em: 25 maio 2020. 
- Nível de proficiência em inglês de professores em formação inicial: um estudo sobre a visão de docentes de um curso de Letras e de especialistas da área

O potencial papel de testes como alavanca de mudanças foi abordado por Shohamy (1992), quando discorreu sobre a introdução do exame de produção oral de língua inglesa em Israel (SHOHAMY; REVESE BEJARANO, 1986), o Guia do Conselho Americano de Ensino de Línguas Estrangeiras (American Council on the Teaching of Foreign Language ACTFL - Guidelines) - e a Entrevista de Proficiência Oral (Oral Proficiency Interview - OPI), nos Estados Unidos. Essa discussão estende-se em Shohamy (1993, p. 186), estudo no qual a autora enfatiza a autoridade dos testes externos:

[...] exames externos tornaram-se aparelhos poderosos capazes de mudar e prescrever o comportamento daqueles afetados por seus resultados administradores, professores e alunos. Agências centrais e aqueles que têm o poder de decisão, cientes da autoridade dos testes externos, os utilizam frequentemente para impor novos programas, materiais didáticos e métodos de ensino. Por isso, testes externos são atualmente usados para motivar alunos a estudar, professores a ensinar e diretores a modificar o programa.

Mesmo quando não envolvem obrigatoriedade de instituições governamentais nem mesmo da escola, exames de proficiência internacionais podem provocar efeito retroativo no ensino e influenciar o estudo da língua, como demonstrou o trabalho de Scaramucci e Kobayashi (2013) sobre o exame da Cambridge, Cambridge English: Key for Schools, realizado no contexto de ensino regular privado no Brasil. Entre os resultados, houve evidências do aumento das horas de estudo da língua, aulas extras de produção oral e reconhecimento dos alunos aprovados no exame junto à escola e ao grupo. Evidências de efeito retroativo positivo junto aos alunos que passaram a se interessar e estudar mais para o TOEFL iBT foram identificadas na investigação de Kobayashi (2016) sobre esse exame no contexto do programa Inglês sem Fronteiras, em uma universidade pública.

Por outro lado, testes são passíveis de provocar efeitos negativos, muitas vezes imprevisíveis, como identificados por Nagao, Tadaki e Wicking (2012) em uma universidade japonesa cujo programa de ensino de inglês era orientado pelo exame PET da Cambridge. As evidências foram encontradas nas atitudes negativas dos docentes que discordavam do conteúdo do teste e do material didático adotado. Já o trabalho de Tsagari (2009) aponta para efeito negativo do Cambridge First Certificate (FCE) na abordagem de ensino, pois, professores não compreendendo a proposta do exame e pressionados por resultados acabavam recorrendo ao test wiseness e a outras técnicas.

Diante disso, a simples implementação de um teste de proficiência não assegura que mudanças relevantes no ensino serão automaticamente viabilizadas, e o nível de proficiência na língua será elevado, pois, seguindo as conclusões de Messick (1996) em 
seu trabalho seminal sobre o tema, um teste pode promover ou inibir o aprendizado da língua na medida em que influencia os professores e alunos a fazerem coisas que não fariam, caso não houvesse o exame.

\section{Metodologia}

Este trabalho caracteriza-se como um estudo de caso de natureza qualitativa que permite uma intensa descrição e o uso de variedade de fontes (MERRIAM, 1988). A investigação qualitativa visa entender os fenômenos por meio dos significados a eles conferidos pelas pessoas e, para tanto, o foco está na análise dos processos e em seus significados (DENZIN; LINCOLN, 2006).

\section{Cenário}

Esta investigação foi conduzida em uma universidade pública que oferece o curso de graduação em Licenciatura em Letras desde 1990, e que atualmente tem as opções: Português/Inglês e Literaturas e Português/Espanhol e Literaturas. O aluno escolhe uma dessas opções ao fazer a inscrição no vestibular da universidade.

O curso tem duração de oito semestres, que totalizam 3.200 horas. Entre as disciplinas da grade curricular, há oito relacionadas diretamente à língua inglesa: leitura, fonética e fonologia, compreensão oral, produção escrita, produção oral, morfossintaxe, gêneros acadêmicos e estágio supervisionado, todas com carga horária de 60 horas, com exceção do estágio que tem 120 horas e um semestre de duração. As literaturas inglesa e norte-americana são ministradas em dois semestres distintos, cada uma com carga horária total de 60 horas. As demais disciplinas do curso abordam aspectos da língua portuguesa e das literaturas brasileira e portuguesa.

A admissão no curso ocorre por meio de dois tipos de processos seletivos aplicados todos os anos, um em janeiro e outro em julho, e o candidato decide em qual deseja efetuar a inscrição. Na seleção de janeiro, é aplicada a prova de vestibular desenvolvida pela universidade, enquanto no meio do ano, o processo seletivo acontece por meio das notas obtidas no Exame Nacional do Ensino Médio (ENEM), instrumento avaliativo elaborado e aplicado pelo Ministério da Educação. Há, no total, quarenta vagas para cada seleção, vinte para os candidatos ao curso de Licenciatura (Português/Inglês) e vinte para Licenciatura (Português/Espanhol). O período para ambos os cursos é noturno. 
- Nível de proficiência em inglês de professores em formação inicial: um estudo sobre a visão de docentes de um curso de Letras e de especialistas da área

\section{Participantes do estudo}

Três professores que ministram as disciplinas relacionadas à língua inglesa e o coordenador do curso integram os participantes da graduação. Dois dos docentes têm o título de mestre. Um deles atua no curso há 17 anos e o outro, há 12 anos (Professor A e Professor B, respectivamente). O Professor C é licenciado em Letras e foi contratado há três anos. O coordenador do curso é doutor em Estudos Literários e trabalha na universidade há 12 anos.

Além desses participantes, foram convidados para este estudo três pesquisadores e docentes da área de ensino e avaliação de língua inglesa que atuam em instituições públicas de renome no Brasil e são autores de livros e publicações científicas que investigam, entre vários tópicos, a formação de professores de língua inglesa, o ensino de inglês e a avaliação em língua estrangeira.

A escolha desses participantes tem o objetivo de trazer vozes distintas, mas que têm em comum a relação dos atores com o problema de pesquisa, de modo que permita a triangulação para assegurar uma compreensão em profundidade (FLICK, 1998) e, mais especificamente, a triangulação de fontes, uma das tendências metodológicas mais utilizadas em pesquisa qualitativa (DENZIN, 1978 apud ALVES-MAZZOTTI; GEWANDSZNAJDER, 1999).

\section{Instrumento de coleta de dados}

A entrevista consistiu no principal instrumento de coleta de dados devido às vantagens que apresenta e a sua adequação ao formato metodológico desta investigação. A sua aplicação ocorre principalmente quando o entrevistador tem interesse em compreender o sentido que os sujeitos atribuem a eventos, processos e situações (MAZZOTTI; GEWANDSZNAJDER, 2001).

Segundo Rubin e Rubin (1995), há vários tipos de formatos de entrevistas qualitativas, que se diferenciam pelo grau de controle existente durante o diálogo, como estruturadas, semiestruturadas, mistas, história oral e história de vida. Especificamente com os participantes que apresentamos neste artigo, foi utilizada a entrevista mista. O controle neste tipo de entrevista é variável, pois há momentos mais estruturados e outros menos. No roteiro, entrevistador e entrevistados envolvem-se em uma conversa que desperta outros questionamentos em prol da investigação. O pesquisador, neste caso, deve atuar elaborando outras questões complementares. Todas as entrevistas foram aplicadas individualmente e tiveram o áudio gravado. 


\section{Discussão dos resultados}

São apresentadas, nesta seção, as discussões dos resultados obtidos junto aos participantes: docentes e coordenadores do curso de Letras e pesquisadores/especialistas da área de ensino e avaliação em língua estrangeira.

As entrevistas com os três professores que ministravam as disciplinas de língua inglesa e o coordenador de curso focalizaram tópicos como o nível de proficiência mínimo esperado para os alunos ingressantes e concluintes do curso de Letras, os problemas mais comuns no desenvolvimento das habilidades linguísticas dos alunos e a utilização de testes de proficiência ao longo do curso. Para evitar diferentes concepções de níveis de proficiência, a descrição geral de cada nível, estabelecida pelo CEFR, foi fornecida a esses participantes.

Primeiramente, sobre o nível de inglês no processo seletivo para os candidatos a uma vaga no curso de Licenciatura em Letras (Português/Inglês e Literaturas), o Professor A acredita que deveria ser, no mínimo, o A1:

Professor A: com o nível Al, eles já teriam o conhecimento das primeiras estruturas, dos primeiros sons, já teriam estudado a posição das palavras e, assim, já entrariam com essa base pronta [...] é muito complicado quando eles entram num curso de língua estrangeira sem saber como funciona essa língua.

No entanto, apesar de admitir que os alunos ingressam em um nível mais baixo e que as razões para tanto estariam relacionadas ao número insuficiente de questões específicas da área nos testes de admissão, o Professor A não é a favor de um teste seletivo de entrada mais específico da língua inglesa. Isto porque tal ação excluiria alunos que poderiam se descobrir como aprendizes bem-sucedidos da língua, ao longo do curso. Mesmo assim, problematiza a cobrança exclusiva da habilidade de leitura e da gramática, nos testes atuais de entrada.

Essa ênfase também foi apontada pelo Professor B como um dos problemas nos testes de entrada no curso de Letras/Inglês. Ele é a favor de um teste mais específico de entrada no curso, sendo o nível A2 o mínimo para aprovação. Caso esse nível não fosse avaliado no ingresso, um teste de nivelamento mais específico seria o ideal, após a aprovação. Todavia, questiona as condições da universidade para desenvolver estratégias de ensino para os diferentes níveis revelados no resultado: 
- Nível de proficiência em inglês de professores em formação inicial: um estudo sobre a visão de docentes de um curso de Letras e de especialistas da área

Professor B: Teria que se ver a possibilidade de trabalhar de modo diferente com esses alunos. Uma coisa seria o ideal, outra coisa, a realidade que a gente tem em sala de aula. A turma teria que ser dividida e ter aulas separadamente. No nosso curso, eu não veja essa possibilidade. Seria importante porque nos daria uma visão da turma que estamos trabalhando.

Quanto à exigência de um teste de proficiência na saída do curso, o Professor B está convicto de que "faria toda a diferença no curso", mas que simulados teriam que ser disponibilizados ao longo do processo para preparar o aluno e também para incentivá-lo a acompanhar o seu desenvolvimento.

Assim como o Professor B, o coordenador do curso também aponta o A2 como o nível mínimo para admissão, mencionado como pré-intermediário que, no entanto, não é a realidade dos alunos ingressantes, segundo ele, devido à precariedade do ensino de inglês nas escolas:

Coordenador: As condições do ensino fundamental de maneira geral, pelo menos até onde eu sei como a língua inglesa é ensinada, em relação ao método e carga horária destinada para a língua e tudo mais.

O participante acredita que a eficiência do vestibular e do ENEM dependem de vários fatores, dentre eles, a nota de corte adotada e os critérios de admissão desses testes (por exemplo, a porcentagem de vagas de ampla concorrência):

Coordenador: Isso vai depender também, da nota de corte, né? De um mínimo, mas, se for pelas questões, sim [acredito na eficácia dos testes], se for consideradas só as questões, mas aí, tem a nota mínima, pelo qual a pessoa entra então, não é só o conteúdo, né? [...] Se for levar em conta o conteúdo sim, mas aí tem a questão da própria seleção, a nota de corte e tudo mais. E aí, mesmo que a pessoa não tenha um bom rendimento, muitas vezes, ela entra por conta da questão da seleção em si e não do conteúdo da prova.

Ele acredita que deveria haver um teste de nivelamento após o ingresso no curso, não somente para a área de inglês, mas para todas as disciplinas do curso. Segundo o coordenador, muitas vezes, os professores, de todas as áreas, nutrem uma expectativa que não é correspondida pelo aluno ingressante, e mesmo assim, adotam uma prática voltada para o perfil da minoria, prejudicando, dessa forma, toda a turma. 
Coordenador: [...] chega um determinado perfil de aluno para nós, na maioria obviamente, porque também chegam alunos mais avançados, mas são alunos com os quais o curso ainda não está sabendo lidar completamente, porque a expectativa é que cheguem alunos mais avançados, e aí, a prática tradicional é mais direcionada pra quem chega mais avançado, mas não é a maioria, então, isso gera uma dificuldade [...] e aí, ao invés da gente se adaptar pra aqueles que precisam mais, nós acabamos mantendo um prática pra aqueles que precisam menos, e aí, os que precisam mais acabam tendo dificuldade e isso atrapalha de maneira geral [...] atrapalha inclusive porque atrasa os mais avançados.

Igualmente, o Professor C elege o nível A2 como adequado para entrada no curso, mas adianta que isso não ocorre devido à baixa qualidade do ensino da disciplina na escola básica e a falta de interesse dos alunos pela língua. Este professor não acredita na eficácia do vestibular nem do ENEM para selecionar ingressantes para o curso de Letras/ Inglês devido à abrangência desses testes, sem uma especificidade para uma ou outra área.

Além disso, o Professor $C$ também citou o fato de somente a habilidade de leitura ser exigida nesses testes. Assim como o Professor B, ele defende a aplicação de um teste mais específico para a entrada. Outros fatores são citados pelo Professor C como determinantes para a deficiência do ensino e aprendizado de uma língua estrangeira na universidade onde aconteceu o estudo:

Professor C: Eles [os alunos] têm um perfil diferenciado, trabalham durante o dia, estudam à noite, eu acho complicado a questão do tempo, mas isso seria uma questão deles, ter controle a mais, autonomia, estudar em casa... eu acho que falta interesse.

Como forma de lidar com os problemas nos testes de admissão, todos os professores e o coordenador demonstram uma posição consensual sobre a necessidade da aplicação de um teste de proficiência diagnóstico para os ingressantes com o objetivo de conhecer as habilidades e competências dos alunos, guiar o desenvolvimento ao longo do curso e identificar as habilidades que precisam ser mais focalizadas. O Professor B, por ministrar a disciplina de leitura em língua inglesa, acredita que o teste diagnóstico deveria focalizar mais nessa habilidade por ser a primeira a ser estudada no curso.

Quanto à aplicação de testes de entrada que exijam um nível mínimo de proficiência, o Professor A e o coordenador são desfavoráveis. Ao contrário, os Professores B e C acreditam que tais testes poderiam selecionar alunos com um perfil mais compatível com o curso. 
- Nível de proficiência em inglês de professores em formação inicial: um estudo sobre a visão de docentes de um curso de Letras e de especialistas da área

Em termos de nível de proficiência em inglês esperado dos concluintes do curso, os pontos de vistas dos docentes variam. O Professor A coloca-se contra a exigência da utilização de teste de proficiência na conclusão do curso por acreditar que poderia intimidar os alunos e influenciar negativamente a escolha do curso de Letras (Português/ Inglês). Quanto ao nível de proficiência a ser atingido, a sua opinião vai ao encontro do estabelecido pelos outros participantes como ideal, que seria o B2. Porém, o Professor A afirma que tal nível seria para aqueles que visam mais do que ensinar em escolas públicas de ensino fundamental e médio, sendo o B2 o suficiente para os graduados, podendo até ser o B1, dependendo do perfil dos alunos e do curso.

Para o Professor B, um teste de proficiência que avaliasse as quatro habilidades linguísticas poderia ser utilizado como um requisito para a graduação, não somente no final, mas ao longo do curso, para que os alunos se familiarizassem com o teste e se preparassem para tal. Embora o nível C2 do CEFR fosse o ideal para um professor de inglês, o Professor B acredita que o B2 seria suficiente. Um dos benefícios que poderia ser provocado pela exigência do teste seria a mudança na atitude dos alunos em relação ao curso. No entanto, este participante afirma que muitos formandos conseguem obter emprego em escolas públicas, mesmo sem ter atingido o nível B2 devido às especificidades desses contextos, que são distintos de escolas particulares e institutos de línguas.

Similarmente, o Professor C também indica que o nível B2 seria o suficiente, tendo em vista as condições estruturais da universidade e o perfil dos alunos, mas enfatiza que o nível $\mathrm{C} 1$ seria o ideal para um professor de inglês. Além disso, assim como o Professor B, o participante defende a aplicação de um teste no final do curso como um requisito para graduação, e de testes de proficiência ao longo do curso, diante da possibilidade de provocar resultados positivos no processo de aprendizagem e melhorar a autoconfiança dos futuros professores.

O coordenador afirma que os documentos norteadores do curso de Letras, como o programa de curso e a grade curricular, estabelecem claramente o nível de proficiência a ser atingido a cada semestre e que, no final da graduação, deveria ser o B2. Entretanto, o participante reconhece que isso não ocorre diante de fatores como a baixa formação educacional e problemas de ordem cultural e social dos alunos.

Como consequência, essas questões relacionadas ao nível de inglês na entrada, durante e na conclusão do curso, acabam por influenciar os alunos que não estão conscientes sobre o nível que devem atingir em cada fase do curso, segundo o coordenador. O participante acrescenta ainda que há a expectativa, entre os alunos, de se aprender a língua do mesmo modo que em escolas de inglês, o que revela que ainda 
não houve a percepção e realização por parte dos estudantes de que a aprendizagem e o ensino estão direcionados à formação de professores da língua.

Dessa forma, o coordenador acredita que muitos alunos podem não estar devidamente preparados para ensinar inglês após a graduação. Mesmo diante dessa realidade, o participante não acredita que estabelecer um teste de proficiência na língua como requisito para a conclusão do curso seja adequado, pois, na sua visão, esse instrumento avaliativo funcionaria como uma seleção e não como aprendizagem.

Apesar dos níveis mencionados pelos professores, tanto de entrada quanto de saída dos alunos, é consenso entre os participantes de que a maioria dos estudantes não têm tal proficiência. Essa realidade apresenta várias motivações, segundo os professores. Entre as razões estão a falta de comprometimento e esforço por parte dos alunos no estudo da língua inglesa, mencionada pelo Professor A e pelo Professor C, e a problemas de estrutura do curso, como a ausência de um laboratório de línguas, citada por todos os professores. O Professor A aponta, ainda, para uma questão que se sobrepõe ao nível de inglês dos ingressantes: as características específicas do curso, como a dupla licenciatura, que possibilita ao aluno ser professor de português ou inglês. Isso, segundo o participante, faz com que muitos ingressantes não tenham o objetivo de se tornarem professores de inglês, o que poderia explicar a falta de empenho no aprendizado e do desenvolvimento da proficiência na língua, conforme salientado pelo Professor C.

Além disso, outros motivos para as dificuldades são indicados individualmente pelos participantes, como baixa autoestima e crenças equivocadas dos alunos de que, por exemplo, o aprendizado da língua é possível em uma viagem internacional de um mês, conforme relato do Professor A, e também o perfil do aluno do curso, integrado por estudantes que trabalham durante o dia e estudam à noite, o que os impediria de alcançar um nível de proficiência mais elevado, de acordo com o Professor C. O coordenador, por outro lado, defende que, uma vez aplicado o teste diagnóstico, a universidade deveria oferecer aulas extras de inglês, baseada nas pontuações atingidas pelos alunos.

\section{Pesquisadores de ensino e avaliação em língua inglesa: a necessidade de quebra do círculo da baixa proficiência}

Três pesquisadores, denominados Pesquisador 1, Pesquisador 2 e Pesquisador 3, da área de ensino e avaliação em língua inglesa de instituições nacionais renomadas e com vasta gama de trabalhos publicados nesse campo foram entrevistados para esta investigação. As questões giraram em torno do nível mínimo de proficiência na língua para entrada e saída do curso de Letras, dos testes atualmente aplicados e dos problemas geralmente encontrados no ensino de inglês nesses cursos de graduação. 
- Nível de proficiência em inglês de professores em formação inicial: um estudo sobre a visão de docentes de um curso de Letras e de especialistas da área

Primeiramente, foi identificado um consenso entre os pesquisadores sobre a inadequação da utilização da prova de inglês do ENEM como instrumento avaliativo em processo seletivo de entrada, baseado no fato de que há um número insuficiente de questões e pelo fato de não avaliar todas as habilidades dos candidatos. Somado a isso, um dos participantes ressalta que cada universidade busca por um perfil específico de estudante por meio dos exames de admissão, ao passo que o ENEM caracteriza-se como um exame padronizado para alunos que estão saindo do ensino médio.

Pesquisador 1: Acho que é [ENEM] tremendamente fraco. Eu não gosto do ENEM como um instrumento de entrada para a universidade. Exame de entrada tem que ser voltado para o perfil de cada universidade... cada universidade tem o seu perfil de aluno.

Por outro lado, os posicionamentos dos pesquisadores apresentam variações diante do nível mínimo de proficiência em inglês exigido para os ingressantes. Considerando o contexto do Pesquisador 1, o B1 seria o suficiente, levando em conta a evolução que os alunos apresentam ao longo do curso. O Pesquisador 2 reforça a importância de um exame específico para o curso de Letras, além do processo de admissão, que atenda o perfil de aluno de cada universidade.

Pesquisador 1: Acho que idealmente...idealmente um nível B1 já ajudaria, facilitaria muito o desenvolvimento linguístico desses alunos, veja que estou pensando muito no meu contexto de atuação, não é, então, eu acredito que muitos alunos entram com um nível inferior ao B1 e conseguem um desenvolvimento bastante satisfatório [...]

Pesquisador 2: Acho que no intermediário superior ou o avançado seria melhor. Talvez um B2 para começar, mas eu penso até um C1 [...]

Para um dos participantes, seria desnecessária a exigência de proficiência mínima. Esta última posição é justificada pelo fato de que se a universidade oferecer um curso intensivo de inglês desde o início da graduação, os alunos atingiriam, no mínimo, o nível B2 no quarto ano. No entanto, os demais pesquisadores acreditam na importância do nível mínimo, pois, na universidade, os alunos devem aprender habilidades para tornarem-se professores e não iniciar o estudo do inglês a partir do básico.

Quanto à aplicação de um teste diagnóstico no ingresso dos alunos, porém, todos os pesquisadores concordam que isso permitiria aos docentes do curso auxiliar os estudantes com o nível mais baixo de proficiência. Além disso, os participantes acreditam 
que os alunos deveriam ser avaliados também antes de se graduarem para atenderem as exigências do mercado de trabalho. Quanto ao nível de proficiência a ser atingido, um pesquisador mencionou o nível $\mathrm{C} 1$ do CEFR, outro o B2, ao passo que o terceiro afirmou que o nível deveria ser estabelecido conforme o programa de curso, que é específico para cada contexto, enquanto o CEFR é para inglês geral.

Pesquisador 3: [...] nós tínhamos uma meta que ele (aluno) chegasse ao $\mathrm{Cl}$ [...] nós tabulamos os dados. Ao final do curso, cinquenta por cento dos alunos chegaram no $\mathrm{Cl}$ e o outro cinquenta que não no $\mathrm{Cl}$, chegou pelo menos no $\mathrm{B} 2$, o que é muito satisfatório.

Para todos os pesquisadores, há sérios problemas na formação de professores de inglês no Brasil, desde as Referências Curriculares Nacionais dos Cursos de Bacharelado e Licenciatura, que deveriam guiar o curso de Letras até o teste de inglês no processo seletivo de admissão do aluno. A falta de clareza e a ausência de um quadro especificando as competências a serem desenvolvidas no curso de Letras foram mencionadas por dois participantes a respeito das Referências.

Os pesquisadores inferiram que uma das razões para a formação deficiente seria o baixo nível de exigência nas disciplinas de inglês para evitar a evasão, por exemplo. Este, por sua vez, poderia ser um dos fatores que contribuiria para que o professor chegasse despreparado na sala de aula, criando, assim, um efeito cíclico, que teria início no processo seletivo da Licenciatura e prosseguiria no ensino de inglês nas escolas. Consequentemente, essa situação poderia afetar o desenvolvimento das competências daqueles alunos que realizassem o ENEM e, eventualmente, ingressassem no curso de Letras, dando início novamente ao ciclo.

\section{Encaminhamentos e reflexões sobre o contexto investigado}

Focalizando a questão fundamental deste artigo, o nível de proficiência em inglês do aluno de Letras e futuro professor dessa língua, os resultados apontam que docentes e coordenador do curso investigado e pesquisadores da área não estão em consenso. Primeiramente, quanto ao nível de inglês do aluno que está se graduando, percebe-se entre os professores que o nível $\mathrm{Cl}$ mostra-se muito distante da realidade em que atuam. Apesar de mencioná-lo como ideal, acabam optando pelo B2 pela justificativa desse nível ser o suficiente e até mesmo o B1. Diante desse resultado, questiona-se por que e para quem o B1 seria adequado? A referência seria o futuro aluno desse professor em formação? Ou a escola, futura empregadora, que não apresenta um perfil tão exigente? 
- Nível de proficiência em inglês de professores em formação inicial: um estudo sobre a visão de docentes de um curso de Letras e de especialistas da área

Torna-se importante ressaltar que o B1 é descrito como um nível pré-intermediário no CEFR e envolve um domínio ainda restrito da língua. Como consequência, pode-se visualizar que, por exemplo, não se espera que um estudante do terceiro ano do ensino médio tenha atingido o CEFR B1, sendo ele aprendiz de um professor de inglês com tal nível.

Por outro lado, os níveis $\mathrm{B} 2$ e $\mathrm{Cl}$ foram mencionados pelos pesquisadores, o que acaba refletindo a posição dos docentes. Embora a proficiência do professor envolva especificidades e habilidades do uso da língua características da prática de ensino, apresentar um nível de proficiência no inglês geral, de acordo com o estabelecido em quadros internacionais de referências, como o $\mathrm{CEFR} \mathrm{Cl}$, possibilita ao aluno lidar com tais especificidades que devem ser exploradas nas disciplinas relacionadas à formação de professor, ou seja, ao como ensinar a língua.

A aplicação de testes de proficiência no fim do curso como requisito para a graduação também não surgiu como ponto pacífico entre os participantes do curso investigado, pois, para os contrários a tanto, a avaliação é vista como um instrumento seletivo e possível inibidor da procura pelo curso. Atitudes contrárias à utilização de teste entre os atores do contexto investigado são comumente identificadas em estudos que evidenciam efeito retroativo negativo (NAGAO; TADAKI; WICKING, 2012; TSAGARI, 2009), reforçando a necessidade de esclarecimentos sobre a proposta do exame. Para os favoráveis, as justificativas revelam consonância com a discussão de Shohamy (1993) sobre a autoridade de testes externos para a promoção de efeito retroativo. A expectativa desses participantes é provocar uma mudança na atitude do aluno, tornando-o mais consciente da necessidade de estudar a língua.

Um dos pontos em comum identificados entre os participantes foi a necessidade de aplicação de um teste diagnóstico no primeiro ano do curso para identificar o nível dos alunos ingressantes. As características de tal avaliação, no entanto, apresentam variações na ótica dos docentes e dos pesquisadores, revelando a complexidade desse instrumento.

Por outro lado, o nível de proficiência exigido para o ingresso do aluno no curso de Letras revelou visões bem distintas, principalmente entre docentes/coordenador e pesquisadores: a variação A1 e A2 foi defendida pelos primeiros e a B1 e B2 apontada pelos segundos. Um dos pontos de reflexão desse resultado está relacionado ao nível de progresso ao longo do curso para que o nível mínimo para a graduação seja atingido, sendo importante ressaltar que a passagem entre os níveis demanda carga horária de estudo para possibilitar o desenvolvimento das habilidades linguísticas. 
Outro ponto em comum está no ingresso do aluno, uma vez que todos os participantes relatam a ineficácia do ENEM como exame de entrada, principalmente em um curso de formação de professores de inglês. Diante desse resultado, um dos encaminhamentos deste estudo aponta para a necessidade de a universidade investigada neste estudo refletir sobre outros exames seletivos que avaliem as expectativas de uso futuro da língua dos alunos de Letras. Quanto a esse aspecto, volta-se a possibilidade da geração de um efeito retroativo positivo de um teste (SHOHAMY; REVESE BEJARANO, 1986; SCARAMUCCI; KOBAYASHI, 2013) que pode influenciar a preparação do futuro aluno do curso de Letras.

É responsabilidade da universidade a formação adequada do professor de inglês e, apesar das possibilidades de melhoria apontadas pelos participantes, tais como, a implementação de laboratórios, cursos extra de inglês, os resultados deste estudo evidenciam a necessidade de quebra do círculo que envolve a formação de professores e futura atuação em escolas. Para tanto, mostra-se imprescindível maior clareza quanto aos níveis de proficiência a serem atingidos pelos alunos em diferentes etapas do curso. Tal dado beneficiaria tanto estudantes quanto docentes. Nesse sentido, a obrigatoriedade da aplicação de instrumentos avaliativos, diante de opiniões distintas dos participantes, deve ser mais profundamente discutida.

\section{Considerações finais}

Este artigo trouxe um recorte dos resultados de um amplo estudo realizado em um curso de licenciatura em Letras (Português/Inglês) de uma universidade pública sobre as expectativas do nível de proficiência em língua inglesa dos alunos em diferentes etapas do curso, e mostrou as vozes de docentes e do coordenador do curso e de pesquisadores de ensino e avaliação de língua estrangeira, distintas em alguns aspectos e convergentes em outros. Revelam-se necessárias reflexões sobre a prova de inglês do processo seletivo do curso por não corresponder à proficiência mínima, traduzidas nas quatro habilidades linguístico-comunicativas, para o acompanhamento das aulas. Somado a isso, o nível de inglês a ser atingido até a saída do aluno e consequente entrada no mercado de trabalho, provavelmente na atuação em escolas, aponta para o B2, mas não de forma unânime. Entretanto, mecanismos de avaliação obrigatória que assegurem essa proficiência do futuro professor não são aceitos por parte dos entrevistados do curso.

Encaminhamentos deste trabalho indicam a necessidade de mais clareza sobre as especificidades das habilidades linguísticas esperadas dos alunos ao longo do curso que poderiam seguir o CEFR ou que com este mantivesse uma equivalência, pelo menos 
- Nível de proficiência em inglês de professores em formação inicial: um estudo sobre a visão de docentes de um curso de Letras e de especialistas da área

até um futuro desenvolvimento de especificações e descritores de proficiência a serem adotados pela universidade. Transparece como urgente esta situação diante do fato de que níveis de proficiência são utilizados comumente como referências no ensino e avaliação de língua e no mercado editorial no âmbito mundial, e o futuro professor de inglês não pode ficar alheio a isso.

Neste sentido, sugere-se o desenvolvimento de estratégias ao longo do curso que minimizem problemas específicos do público-alvo da universidade, tais como, a baixa formação educacional dos ingressantes, problemas culturais e sociais apontados pelo coordenador do curso. Tais estratégias iriam ao encontro de um nível de aprendizagem que poderia influenciar positivamente na identidade profissional do professor de línguas.

\section{Referências}

ALDERSON, J. C.; WALL, D. Does washback exist? Applied Linguistics, v. 14, p. 115-129, 1993.

ALMEIDA FILHO, J. C. P. O professor de língua estrangeira sabe a língua que ensina?

Contexturas, v. 1, n. 1, p. 77-85, 1992.

ALVES-MAZZOTTI, A. J.; GEWANDSZNAJDER, F. O método nas ciências naturais e sociais: pesquisa quantitativa e qualitativa. 2. ed. São Paulo: Pioneira, 1999.

BRASIL. Ministério da Educação e Cultura. (2001). Parecer CNE/CP nº 492/2001, de 03 de abril. Diretrizes Curriculares Nacionais dos Cursos de História, Filosofia, Geografia, Serviço Social, Letras, Biblioteconomia, Arquivologia e Museologia. Disponível em: http://portal.mec.gov.br/cne/arquivos/pdf/CES0492.pdf. Acesso em: 20 abr. 2021.

CHENG, L. How does washback influence teaching? Implications for Hong Kong. Language and Education, v. 11, n. 1, p. 38-54, 1997.

CHENG, L. Changing language teaching through language testing. Studies in language testing, v. 21, 2005.

CONSOLO, D. A.; TEIXEIRA DA SILVA, V. L. The TEPOLI test: construct, updated tasks and new parameters to assess EFL teachers' oral proficiency. In: I Congresso Internacional da ABRAPUI. Belo Horizonte: UFMG, 2007. CD-ROM. 
CONSOLO, D. A.; TEIXEIRA DA SILVA, V. L. Em defesa de uma formação linguística de qualidade para professores de línguas estrangeiras: o exame EPPLE. Revista Horizontes de Linguística Aplicada, v. 13, n. 1, 20 abr. 2015. Disponível em: https://doi. org/10.26512/rhla.v13i1.1334. Acesso em: 12 jan. 2019.

CRYSTAL, D. English as a Global Language. 2nd. ed. Cambridge: Cambridge University Press, 2003.

DENZIN, N.; LINCOLN, Y. O planejamento da pesquisa qualitativa: teorias e práticas. Tradução Sandra Regina Netz. Porto Alegre: Armed, 2006.

FERMAN, I. The Washback of an EFL National Oral Matriculation Test to Teaching and Learning. In: CHENG, L.; WATANABE, Y.; CURTIS, A. Washback in language testing: Research contexts and methods. Mahwah, NJ: Lawrence Erlbaum, 2004. p. 191-211.

FLICK, U. An introduction to qualitative research: Theory, method and applications. London: Sage, 1998.

GALLARDO, B. C.; OLIVEIRA, W. C. D. de. Considerações sobre a formação do professor de inglês em um mundo globalizado. Entrepalavras, Fortaleza, v. 8, n. 3, p. 300-319, out./ dez. 2018. Disponível em: http://www.entrepalavras.ufc.br/revista/index.php/Revista/ article/view/1274/551. Acesso em: 10 ago. 2020.

GIMENEZ, T. Referências para a formação de professores de inglês como língua estrangeira/adicional. In: FINARDI, K. R.; TÍLIO, R.; BORGES, V.; DELLAGNELO, A.; RAMOS FILHO, E. (org.). Transitando e Transpondo n(a) Linguística aplicada. Campinas: Pontes, 2019. p. 243-265.

GIMENEZ, T. Proficiência lingüística de futuros professores de inglês. In: GIMENEZ, T.; CRISTOVÃO, V. L. (org.). ENFOPLI: Construindo uma comunidade de formadores de professores de inglês, 2005. p. 29-34.

GIMENEZ, T.; MATEUS, E. F. Conhecimento local e conhecimento estrangeiro: um olhar retrospectivo sobre o Programa Paraná ELT. In: JORDÃO, C.; GIMENEZ, T.; ANDREOTTI, V. (org.). Perspectivas Educacionais e Ensino de Inglês na Escola Pública. Pelotas: EDUCAT, 2002. p. 161-178. 
- Nível de proficiência em inglês de professores em formação inicial: um estudo sobre a visão de docentes de um curso de Letras e de especialistas da área

GRADDOL, D. The future of English? The British Council, 2000. Disponível em: https:// www.britishcouncil.jp/sites/default/files/eng-future-of-english-en.pdf. Acesso em: 15 fev. 2020.

JENKINS, J. The phonology of English as an international language. Oxford: Oxford University Press, 2000.

LANKSHEAR, C. Language and the new capitalism. The International Journal of Inclusive Education, v.1, n. 4, p. 309-321, 1997.

LEFFA, V. J. O professor de línguas estrangeiras: do corpo mole ao corpo dócil. In: FREIRE, M. M.; ABRAHÃO, M. H. V.; BARCELOS, A. M. F. (org.). Linguística Aplicada e contemporaneidade. São Paulo: ALAB; Pontes, 2005. p. 203-218.

LUMLEY, T.; STONEMAN, B. Conflicting perspectives on the role of test preparation in relation to learning. Hong Kong Journal of Applied Linguistics, v. 5, n. 1, p. 50-80, 2000.

MARCELINO, R. G. A proficiência do professor de inglês como LE: uma análise das Diretrizes Curriculares e dos Projetos Pedagógicos de três cursos de Letras. 2010. Dissertação (Mestrado em Linguística Aplicada) - Instituto de Estudos da Linguagem, Universidade Estadual de Campinas, Campinas, 2010.

MERRIAM, S. B. Case Study Research in Education: a Qualitative Approach. San Francisco: Jossey-Bass, 1988.

MESSICK, S. Validity and washback in language testing. Language testing, v. 13, n. 3, p. 241-256, 1996.

NAGAO, J.; TADAKI, T.; TAKEDA, M.; WICKING, P. The attitudes of teachers and students towards a PET-based curriculum at a Japanese University. Research Notes, v. 47, p. 27-36, 2012.

PAIVA, V. L. M. O. Ilusão, aquisição ou participação. In: LIMA. D. C. (org.). Inglês na escola não funciona: uma questão, múltiplos olhares. São Paulo: Parábola, 2011. p. 33-46.

PAIVA, V. L. M. O. Avaliação dos cursos de Letras e a formação do professor. Revista do GELNE, João Pessoa. v. 5, n. 1 e 2, p. 193-200, 2004. 
PAIVA, V. L. M. O. A LDB e a legislação vigente sobre o ensino e a formação de professor de língua inglesa. In: STEVENS, C. M. T.; CUNHA, M. J. (org.). Caminhos e Colheitas: ensino e pesquisa na área de inglês no Brasil. Brasília: UnB, 2003. p. 53-84. Disponível em: http://www.veramenezes.com/publicacoes.html. Acesso em: 03 jun. 2020.

RUBIN, H. J.; RUBIN, I. S. Qualitative interviewing: the art of hearing data. London: Sage Publications, 1995.

SCARAMUCCI, M. V. R.; KOBAYASHI, E. Washback effect of Cambridge English: Key for Schools in São Paulo city, Brazil: A case study. Research Notes, v. 54, 2013.

SHOHAMY, E. The power of tests: The impact of language tests on teaching and learning. NFLC Occasional Paper. Washington, DC: National Foreign Language Center, 1993.

SHOHAMY, E. Beyond Proficiency Testing: A Diagnostic Feedback Testing Model for Assessing Foreign Language Learning. Modern Language Journal, v. 76, p. 513-521, 1992.

SHOHAMY, E.; REVES, T.; BEJARANO, Y. Introducing a new comprehensive test of oral proficiency. ELT Journal, v. 40, p. 212-220, 1986.

TSAGARI, D. The Complexity of Test Washback. Language Testing and Evaluation, v. 15, 2009.

QI, L. Has a High-stakes test produced the intended changes? In: CHENG, L.;

WATANABE, Y; CURTIS, A. (ed.). Washback in Language Testing Research Contexts and Methods. New Jersey: Lawrence Erlbaum Associates, 2004. p. 171-190.

WALKER, S. Uma visão geral do ensino de inglês no Brasil. In: STEVENS, C. M. T.; CUNHA, M. J. (org.). Caminhos e colheitas: ensino e pesquisa na área de inglês no Brasil. Brasília: Ed. Universidade de Brasília, 2003. p. 35-42.

WATANABE, Y. Methodology in Washback Studies. In: CHENG, L.; WATANABE, Y.; CURTIS, A. (ed.). Washback in Language Testing: Research Context and Methods. Mahwah. New Jersey: Lawrence Erlbaum Associates, 2004. p. 19-36. 
- Nível de proficiência em inglês de professores em formação inicial: um estudo sobre a visão de docentes de um curso de Letras e de especialistas da área

COMO CITAR ESTE ARTIGO: KOBAYASHI, Eliana; GALLARDO, Barbara Cristina. Nível de proficiência em inglês de professores em formação inicial: um estudo sobre a visão de docentes de um curso de Letras e de especialistas da área. Revista do GEL, v. 18, n. 2, p. 66-87, 2021. Disponível em: https://revistadogel. gel.org.br/ 